\title{
Hunger in Africa, Land of Plenty
}

\author{
By Anis (Anisuzzaman) Chowdhury Co-editor, Journal of the Asia Pacific \\ Economy Adjunct Professor, University of New South Wales \& Western Sydney \\ University \\ and \\ Jomo KS, Co-author, Ending Malnutrition. FAO, 2015
}

SYDNEY and KUALA LUMPUR, Oct 14 (IPS) - Globally, 108 million people faced food crises in 2016, compared to about 80 million in 2015 - an increase of 35\%, according to the 2017 Global Report on Food Crises. Another 123 million people were 'stressed', contributing to around 230 million such food insecure people in 2016, of whom 72\% were in Africa.

The highest hunger levels are in Sub-Saharan Africa (SSA) according to the Global Hunger Index 2016. The number of 'undernourished' or hungry people in Africa increased from about 182 million in the early 1990s to around 233 million in 2016 according to the FAO, while the global number declined from about a billion to approximately 795 million.

This is a cruel irony as many countries in Africa have the highest proportion of potential arable land. According to a 2012 FAO report, for African sub-regions except North Africa, between $21 \%$ and $37 \%$ of their land area face few climate, soil or terrain constraints to rain-fed crop production.

\section{Why hunger?}

Observers typically blame higher population growth, natural calamities and conflicts for hunger on the continent. And since Africa was transformed from a net food exporter into a net food importer in the 1980s despite its vast agricultural potential, international food price hikes have also contributed to African hunger.

The international sovereign debt crises of the 1980s forced many African countries to the stabilization and structural adjustment programmes (SAPs) of the Bretton Woods institutions. Between 1980 and 2007, Africa's total net food imports grew at an average of 3.4\% per year in real terms. Imports of basic foodstuffs, especially cereals, have risen sharply.

One casualty of SAPs was public investment. African countries were told that they need not invest in agriculture as imports would be cheaper. . Tragically, while Africa deindustrialized thanks to the SAPs, food security also suffered.

In 1980, Africa's agricultural investments were comparable to those in Latin America and Caribbean (LAC). But while LAC agricultural investment increased 2.6 fold between 1980 and 2007, it increased by much less in Africa. Meanwhile, agricultural investments in Asia went 
from three to eight times more than in Africa as African government investments in agricultural research remained paltry.

Thus, African agricultural productivity has not only suffered, but also African agriculture remains less resilient to climate change and extreme weather conditions. Africa is now comparable to Haiti where food agriculture was destroyed by subsidized food imports from the US and Europe, as admitted by President Clinton after Haiti's devastating 2010 earthquake.

\section{Lost decades}

SAP advocates promised that private investment and exports would soon follow cuts in public investment, thus paying for imports. But the ostensibly short-term pain of adjustment did not bring the anticipated long-term gains of growth and prosperity. Now, it is admitted that 'neoliberalism' was 'oversold', causing the 1980s and 1990s to become 'lost decades' for Africa.

Thanks to such programmes, even in different guises such as the Poverty Reduction Strategy Papers (PRSPs), Africa became the only continent to see a massive increase in poverty by the end of the 20th century. And despite the minerals-led growth boom for a dozen years (20022014) during the 15 years of the Millennium Development Goals, nearly half the continent's population now lives in poverty.

The World Bank's Poverty in Rising Africa shows that the number of Africans in extreme poverty increased by more than 100 million between 1990 and 2012 to about 330 million. It projects that "the world's extreme poor will be increasingly concentrated in Africa".

\section{Land grabs}

Despite its potential, vast tracts of arable land remain idle, due to decades of official neglect of agriculture. More recently, international financial institutions and many donors have been advocating large-scale foreign investment. A World Bank report notes the growing demand for farmland, especially following the 2007-2008 food price hikes. Approximately 56 million hectares worth of large-scale farmland deals were announced in 2009, compared to less than four million hectares yearly before 2008. More than 70\% of these deals involved Africa.

In most such deals, local community concerns are often ignored to benefit big investors and their allies in government. For example, Feronia Inc - a company based in Canada and owned by the development finance institutions of various European governments - controls 120,000 hectares of oil palm plantations in the Democratic Republic of Congo.

Advocates of large-scale land acquisitions claim that such deals have positive impacts, e.g., generating jobs locally and improving access to infrastructure. However, loss of community access to land and other natural resources, increased conflicts over livelihoods and greater inequality are among some common adverse consequences.

Most such deals involve land already cleared, with varied, but nonetheless considerable socioeconomic and environmental implications. Local agrarian populations have often been dispossessed with little consultation or adequate compensation, as in Tanzania, when Swedish- 
based Agro EcoEnergy acquired 20,000 hectares for a sugarcane plantation and ethanol production.

Land grabbing by foreign companies for commercial farming in Africa is threatening smallholder agricultural productivity, vital for reducing poverty and hunger on the continent. In the process, they have been marginalizing local communities, particularly 'indigenous' populations, and compromising food security.

This article is part of a series of stories and op-eds launched by IPS on the occasion of this year's World Food Day on October 16.

Visit this story at http://ipsnews.net/2017/10/hunger-africa-land-plenty 